Organo- and

\title{
Formal Enzymatic Reductive Amination with Ammonia
}

\section{Key words}

reductive amination

enzymes

transaminases

alcohol

dehydrogenases<smiles>[3H]C([3H])=O</smiles>
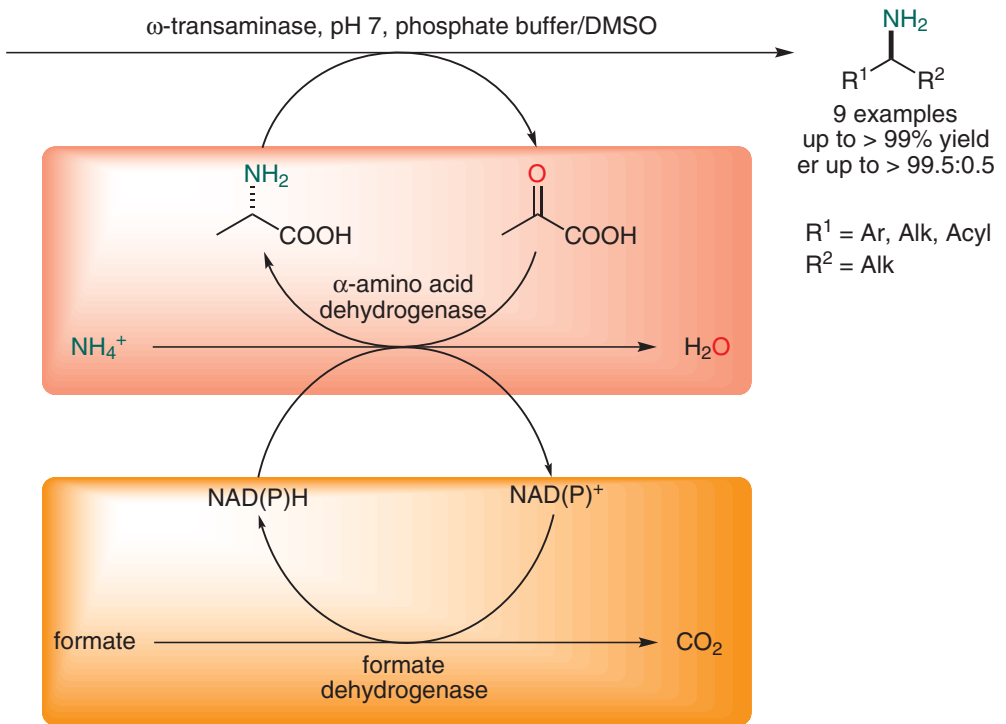

$\mathrm{R}^{1}=\mathrm{Ar}$, Alk, Acyl

$\mathrm{R}^{2}=$ Alk

Significance: The authors report a biocatalytic reductive amination of ketones. The transformation is catalyzed by a combination of three different enzymes, a transaminase, an alanine dehydrogenase and a formate dehydrogenase. Under consumption of alanine to pyruvate, the products are formed with high yields and outstanding enantioselectivities. The recycling of alanine and the co-factor $\mathrm{NAD}(\mathrm{P}) \mathrm{H}$ is effected by ammonium formate in two independent enzymatic operations, producing water and $\mathrm{CO}_{2}$ as only by-products.
Comment: Reductive amination is one of the most powerful and versatile methods for the preparation of amines from simple carbonyl compounds. The reported mild and efficient procedure shows the high potential of enzymes. Further investigations can give rise to more sophisticated and complex molecules involving biocatalysis. Beside several metal- and organocatalytic methods, this procedure represents a complementary and green approach towards nitrogen-containing molecules. 